\title{
EKG-gyöngyszem: a Brugada-jel
}

\author{
Tomcsányi János dr.
}

A Betegápoló Irgalmasrend Budai Irgalmasrendi Kórháza, Budapest

\begin{abstract}
Palpitációs panasz miatt vizsgált vietnami betegnél az EKG I-es típusú Brugada-jelet mutatott, felrostozott QRSekkel. A Brugada-EKG korai felismerése, majd a beteg arrhythmiakockázatának felmérése a legfontosabb feladat. Orv Hetil. 2018; 159(45): 1848-1850.
\end{abstract}

Kulcsszavak: Brugada-szindróma, QRS-felrostozottság, korai repolarizáció, hirtelen szívhalál

\section{ECG pearl: the Brugada sign}

\section{Case report}

An Asian patient was admitted with palpitation. The ECG showed coved-shaped type Brugada pattern with QRSfragmentations. Early recognition and risk stratification are the most important issues in Brugada syndrome.

Keywords: Brugada syndrome, fragmentation of QRS, early repolarization, sudden cardiac death

Tomcsányi J. [ECG pearl: the Brugada sign. Case report.] Orv Hetil. 2018; 159(45): 1848-1850.

(Beérkezett: 2018. június 29.; elfogadva: 2018. július 12.)

\section{Rövidítések}

$\mathrm{EKG}=$ elektrokardiogram; ER = (early repolarization $)$ korai repolarizáció; ERP = effektív refrakter periódus; $\mathrm{HSZH}=$ hirtelen szívhalál; ICD = (implantable cardiac defibrillator) beültethetô újraélesztő készülék; PRELUDE = PRogrammed ELectrical stimUlation preDictive valuE; $\mathrm{VF}=$ (ventricular fibrillation) kamrafibrilláció

\section{Esetismertetés}

Egy 42 éves, hazánkban élő vietnami férfi beteg palpitációs panasz miatt jelentkezett orvosi vizsgálatra, amelynek során az 1 . ábrán látható EKG készült. Panasza ekkor már nem volt. Anamnézisében érdemi betegség nem szerepel, syncopés rosszulléte nem volt. Gyógyszert nem szed. Elmondása szerint rokonai közül egyedül az édesanyja hunyt el hirtelen szívhalállal 60 éves korában. Két testvére Vietnamban él, egészségesek. Laborvizsgálata, szívultrahang-vizsgálata kórosat nem mutatott. A nyugalmi EKG-eltérés és a palpitációs panasz miatt 48 órás Holter-vizsgálat történt, szintén negatív eredménnyel. Az elektrofiziológiai vizsgálat során (a jobbkamra-csúcsból, kiáramlási pályából 600 és 400 milliszekundumos (ms) hajtással 3-as stimuláció történt) a jobb kamrai ERP-je 220 ms volt, és tartós ritmuszavar nem volt indukálható. A beteg ICD-implantációban részesült.

\section{EKG-analízis}

A felvételi EKG-n sinusrhythmus mellett a V1-2-elvezetésekben látható jobb-Tawara-szár-blokk mintájú QRS, deszcendáló ST-elevációval és negatív T-hullámmal. A V3-elvezetésben pedig emelt J-pont melletti nyereg alakú ST-eleváció látszik. A kép megfelel a típusos Brugada EKG-jelnek (I. típus) [1]. Emellett az inferior III-aVFelvezetésekben korai repolarizációnak (ER) megfelelő igen kifejezett emelt J-pont látható (nyilak). A V2-elvezetésben pedig a QRS felrostozottsága jelentkezik (nyilak). A QRS-felrostozottság Brugada-jel esetén azt jelenti, hogy legalább 4 tüske van a QRS-en belül [2]. Az ER jele a J-pont $\geq 1 \mathrm{~mm}$-es elevációja [3].

\section{Megbeszélés}

A Brugada-szindróma az idiopathiás kamrafibrilláció (VF) megkülönböztetett formája, amely unikális EKGeltéréssel jár: jobb-Tawara-szár-blokk mintájú QRS-eket praecordialis ST-eleváció kísér a Vl-3-elvezetésekból legalább kettőben.

Számos vizsgálat igazolta, hogy azon egyének, akiknek syncopéjük volt, és praecordialis ST-elevációjuk úgynevezett coved-shaped típusú (magyar fordítása nincs, 


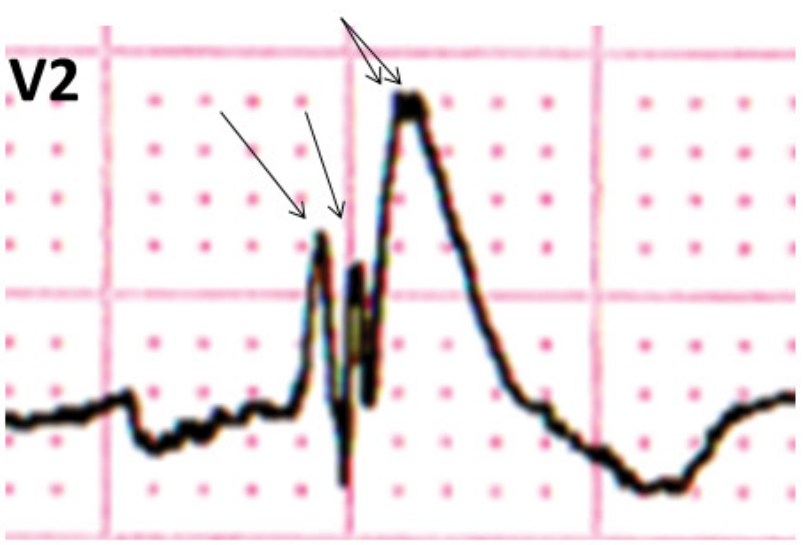

I.

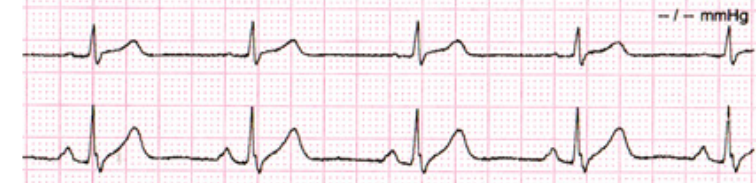

II.

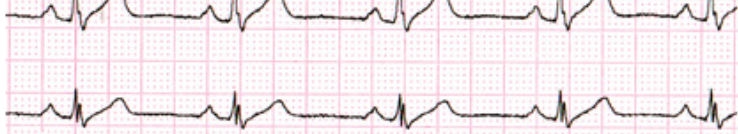

III.

aVR.

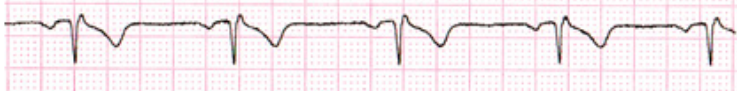

aVL.

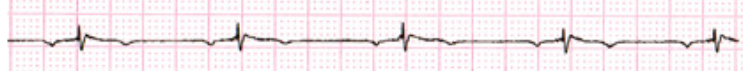

aVF.
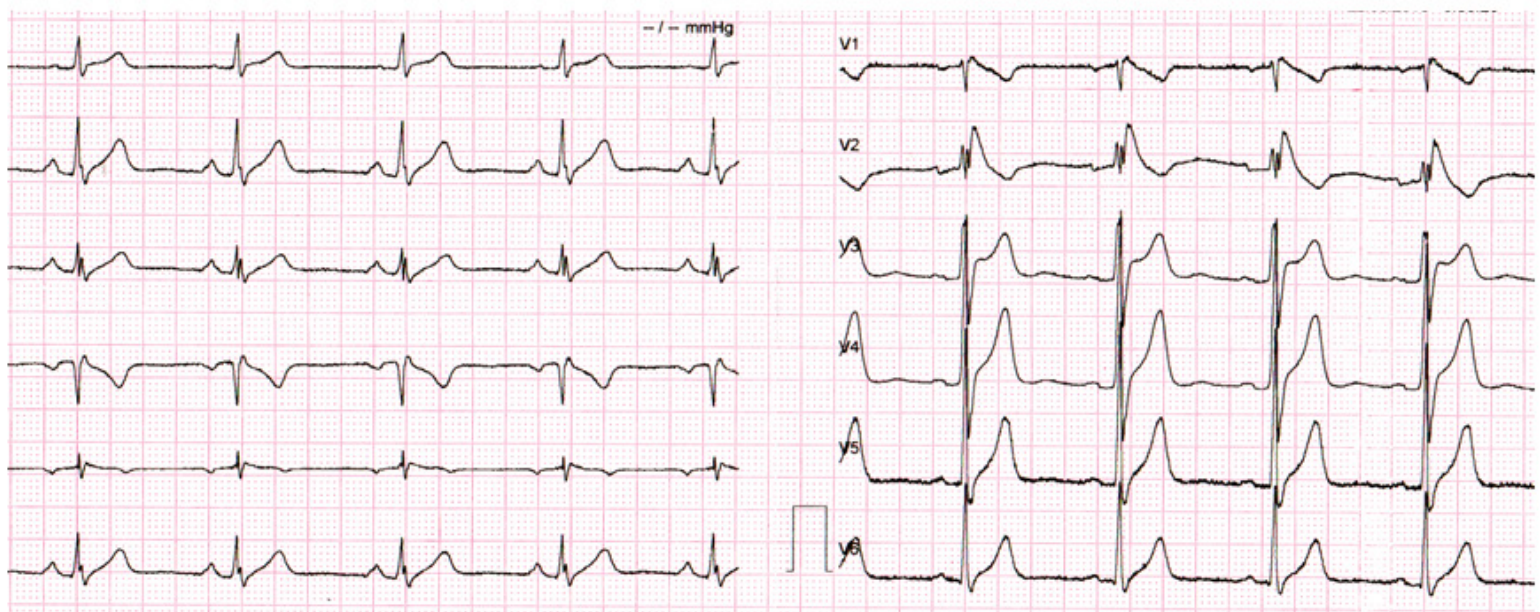

1. ábra

12 elvezetéses EKG. A Vl-2-elvezetés a jobb-Tawara-szár-blokk mellett az elevált J-pontból induló deszcendáló ST-szakaszt (coved ST-eleváció) és negatív T-hullámot mutat. A kinagyított rész a nyilakkal a QRS felrostozottságát mutatja

én leginkább vitorlajelnek írnám le), a hirtelen szívhalál (HSZH), illetve a VF magas rizikójának vannak kitéve $[4,5]$.

Napjaink két legfontosabb problémája a Brugadaszindróma kapcsán a korai felismerés (fóleg gyerekeknél aktuális, hogy ne az első tünet legyen az utolsó tünet), illetve a tünetmentes egyének rizikóstratificatiója. Újabb vizsgálatok azt mutatták, hogy azok, akiknek felrostozott a QRS-ük (depolarizációs zavar), illetve inferolateralis korai repolarizációjuk van, a HSZH, illetve a VF magas rizikójának vannak kitéve [6,7]. Egy ilyen jeleket mutató EKG került most bemutatásra, azzal az üzenettel, hogy az ilyen EKG-eltéréseket mutató pácienseket panaszmentes esetben is mindenképpen elektrofiziológushoz javasolt irányítani. Habár Brugada-szindrómáról és Brugada EKG-jeleket mutató egyéb betegségekrôl volt már hazai közlés $[8,9]$, I. típusú ST-elevációhoz társuló felrostozott QRS-t mutató EKG még nem került bemutatásra. Ezek felismerése azért is lényeges, mert a rizikó megítélésének szempontjából fontosabbak, mint az elektrofiziológiai vizsgálat, amelynek során a PRELUDE-regiszter azt mutatta, hogy a programozott elektrostimuláció nem segít ezen betegek rizikójának megítélésében [10]. A jelenleg érvényes ajánlás csak az abortált szívhalál, dokumentált malignus rhythmuszavar és a syncope esetén javasolja egyértelmúen az ICD-implantációt [11], ezért a jelen esetben a beültetés „off label” volt. Azért kapott mégis ICD-t a beteg, mert egyrészt az újabb vizsgálatok igazolták a bemutatott EKG-rizikómarkerek fontosságát, másrészt az édesanya hirtelen halála is rizikótényezőt jelentett. Habár az édesanya életkora alapján nem biztos a primer arrhythmia okozta halál, de Priori és mtsai felmérése alapján [12] a Brugada-szindrómás betegeknél a VF fellépte sem szokott túl korán jelentkezni (41 \pm 15 év).

Anyagi támogatás: A közlemény megírása anyagi támogatásban nem részesült.

A szerző a cikk végleges változatát elolvasta és jóváhagyta.

Érdekeltségek: A szerzőnek nincsenek a cikk megírásával, illetve tartalmával kapcsolatban érdekeltségei. 


\section{Irodalom}

[1] Brugada P, Brugada J. Right bundle branch block, persistent ST segment elevation and sudden cardiac death: a distinct clinical and electrocardiographic syndrome. A multicenter report. J Am Coll Cardiol. 1992; 20: 1391-1396.

[2] Morita H, Kusano KF, Miura D, et al. Fragmented QRS as a marker of conduction abnormality and a predictor of prognosis of Brugada syndrome. Circulation 2008; 118: 1697-1704.

[3] Sarkozy A, Chierchia GB, Paparella G, et al. Inferior and lateral electrocardiographic repolarization abnormalities in Brugada syndrome. Circ Arrhythm Electrophysiol. 2009; 2: 154-161.

[4] Brugada J, Brugada R, Brugada P. Determinants of cardiac sudden death in individuals with the electrocardiographic pattern of Brugada syndrome and no previous cardiac arrest. Circulation 2003; 108: 3092-3096.

[5] Eckardt L, Probst V, Smits JP, et al. Long-term prognosis of individuals with right precordial ST-segment-elevation Brugada syndrome. Circulation 2005; 111: 257-263.

[6] Tokioka K, Kusona KF, Morita H, et al. Electrocardiographic parameters and fatal arrhythmic events in patients with Brugada syndrome: combination of depolarization and repolarization abnormalities. J Am Coll Cardiol. 2014; 63: 2131-2138.

[7] Conte G, de Asmundis C, Sieira J, et al. Prevalence and clinical impact of early repolarization pattern and QRS-fragmentation in high-risk patients with Brugada syndrome. Circ J. 2016; 80: 2109-2116.

[8] Tomcsányi J, Sármán B. Simultaneous presentation of Brugada syndrome and primary aldosteronism. (Brugada-szindróma és primer aldosteronismus együttes előfordulás.) Orv Hetil. 2012; 153: 1797-1799. [Hungarian]

[9] Tomcsányi J. Brugada phenocopy. (Brugada-fenokópia.) Orv Hetil. 2016; 157: 495-499. [Hungarian]

[10] Priori SG, Gasparini M, Napolitano C, et al. Risk stratification in Brugada syndrome. Results of the PRELUDE (PRogrammed ELectrical stimUlation preDictive valuE) Registry. J Am Coll Cardiol. 2012; 59: 37-45.

[11] Priori SG, Blomström-Lundqvist C, Mazzanati A, et al. 2015 ESC Guidelines for the management of patients with ventricular arrhytmias and the prevention of sudden cardiac death summarized by co-chairs. Eur Heart J. 2015; 36: 2757-2759.

[12] Priori SG, Napolitano C, Gasparini M, et al. Natural history of Brugada syndrome: insights for risk stratification and management. Circulation 2002; 105: 1342-1347.

(Tomcsányi János dr., Budapest, Árpád fejedelem útja 7., 1023 e-mail: tomcsanyij@gmail.com)

\section{"Homo totiens moritur quotiens amittit suos." \\ (Annyiszor hal meg az ember, ahányszor elveszít valakit az övéi közül.)}

\section{Eladó praxis}

Balatonfüreden házi gyermekorvosi praxis, jól felszerelt rendelővel eladó.

Szakképzett, precíz asszisztencia biztositott.

Kedvező körülmények és feltételek adottak.

Nyugdíjba vonulási szándék miatt keresem az utódomat.

Praxislétszám: 650 fö.

Elérhetőség: +36/30 2197360 